American Journal of Applied Sciences 7 (1): 145-152, 2010

ISSN 1546-9239

(C) 2010 Science Publications

\title{
Takagi-Sugeno Fuzzy Gains Scheduled PI Controller for Enhancement of Power System Stability
}

\author{
${ }^{1}$ Lokman H. Hassan, ${ }^{1}$ M. Moghavvemi and ${ }^{2}$ Haider A.F. Mohamed \\ ${ }^{1}$ Centre for Research in Applied Electronics, University of Malaya, 50603 Kuala Lumpur, Malaysia \\ ${ }^{2}$ Department of Electrical and Electronic Engineering, \\ University of Nottingham Malaysia Campus, Malaysia
}

\begin{abstract}
Problem statement: Power system oscillations affect system stability and may lead to failure if not properly controlled. Approach: A Takagi-Sugeno Fuzzy Gains Scheduled Proportional and Integral (FGPI) controller was proposed for a Thyristor Controlled Series Capacitor (TCSC)-based stabilizer to enhance the power system stability. Linguistic rules and fuzzy inference mechanism are utilized to tune the controller parameters on-line in different operating states. The proposed controller was applied to a single machine infinite bus system represented by the Phillips-Heffron generator model. Simulation studies have been carried out using MATLAB Fuzzy Logic toolbox. Simulated Annealing-based Power System Stabilizer (SAPSS) and Simulated Annealing-based TCSC Stabilizer (SACSC) approaches were also simulated in this study and their results were compared with proposed controller. Results: The simulation results demonstrated that the proposed control scheme performs well and strongly control the power system under different loading conditions, disturbances and system parameter variations. Conclusion: The proposed controller is robust and more suitable for damping of low frequency oscillation and more effective in improving dynamic stability and voltage profile than the two other approaches.
\end{abstract}

Key words: TCSC, low frequency oscillation, Takagi-Sugeno fuzzy control, gain scheduling control

\section{INTRODUCTION}

A strong acting Automatic Voltage Regulator (AVR) may avert a loss of synchronism after a fault take place and is cleared in perceptible manner. This happens by exerting control over the amount of the dc excitation current circulated by the exciter to bring out the magnetic field inside the generator. Subsequent to any disturbance the damper and the field winding attempt to damp rotor swing. The damping process repels by the negative damping torques introduced by AVR (Machowiski et al., 1998). As a result, the power system may be exposed to undesirable oscillations or lose of synchronism. Subsequently, these oscillations in a power system restrict the operating capability of power transmission; jeopardize system security and reduce the operating efficiency of the power system. With these conditions, researchers were continually tasked to find simple, effective and economical strategy of attaining stabilization of the power system which is considered of highest priority. This concern resulted in the Power System Stabilizer (PSS) becoming technologically advanced and expanded to serve for an effective functioning. Hence, the PSS emerged as a simple and cost-effective approach.

It has to be mentioned that some studies acknowledge that conventional practices of PSS method may adversely affect voltage profile; result in leading power factor and may not be able to suppress oscillations resulting from severe disturbances, specially those three-phase fault which may occur at the generator terminals. In these cases, other effective solutions need to be studied.

Flexible Alternating Current Transmission Systems (FACTS) devices were introduced in the late 1980. These devices operate at fast speed so they can be used to control power system in a smooth, continuous state with better system stability and damping of the low-frequency oscillations (Khan et al., 2004; Gerbex et al., 2001; Paserba, 2004).

One of these FACTS devices is Thyristor-Controlled Series Capacitor (TCSC) that can provide rapid speed control of active power through a transmission line. The ability to control the transmittable power suggests the potential application of these devices for damping of the low-frequency oscillations.

Corresponding Author: Lokman H. Hassan, Centre for Research in Applied Electronics, University of Malaya, 50603 Kuala Lumpur, Malaysia 
Various control techniques have been utilized by many researchers for PSS and FACTS based stabilizer. These includes conventional control techniques based classical control theory and linear optimal control. These are control techniques designed to improve power systems dynamics. These methods were developed based on some assumptions. Power system is a nonlinear, complex system and is subjected to different kinds of events that yield unresolved issues and uncertain consequences in different power system problems. Considering these limitations, it is difficult to effectively solve the significant power system control problems depending only on these approaches. Therefore, other types of modern control techniques like adaptive controller and $\mathrm{H}_{\infty}$ control system were used to achieve better operating performance as distinguished from conventional controllers. With these the control parameters can be adjusted quickly and continuously according to changes in demand (Hang et al., 1993). The designing of the controllers based on modern control theory suffers from some technical problems; the comprehensive information about the power system is required and need large computing time for on-line parameter identification and thus high implementation costs.

Artificial Intelligence (AI) techniques proved to be effective tools to resolve many power system problems and can be more effective when properly joined together with conventional mathematical approaches (He et al., 2005; Venayagamoorthy, 2005; Barreiros et al., 2005; Al-Awami et al., 2007; Gouveia and Matos, 2009; Qureshi et al., 2007). Different supplementary controllers were proposed for TCSC devices based on AI techniques (Tan et al., 1998; 2000; Lu et al., 2002; Abido, 2000; Abdel-Magid and Abido, 2004; Dash and Mishra, 2003).

One of these AI techniques is Fuzzy logic which has been effectively applied to design controllers for TCSC devices especially Takagi-Sugeno fuzzy which is computationally efficient and performs well with linear techniques (e.g., PI or PID control), optimization and adaptive techniques (Dash and Mishra, 2003).

In the process of exploring effective tools to find solution to many power system problems, this study introduces a new Fuzzy Gain Schedule Proportional and Integral (FGPI) controller for control of TCSC device in Single Machine Infinite Bus (SMIB) system. Here, Takagi-Sugeno fuzzy is used to implement the proposed controller. Assessment of results of the proposed controller are compared and evaluated using an approach proposed by (Abido, 2000) as benchmark. Employs Simulated Annealing (SA) optimization technique to search for the optimal lead-lag stabilizer parameters of the TCSC-based stabilizer and PSS (Abido, 2000).
Nonlinear simulation and the performance robustness demonstrate ability of the proposed approach in damping of low-frequency oscillations over a wide range of loading conditions, disturbances and system parameter variations. In addition, the voltage profile and dynamic stability of the system are more advanced. The results determine with certainty that the proposed fuzzy logic controller performs a function better than the other strategies.

\section{MATERIALS AND METHODS}

Phillips-Heffron model of power system with TCSC: A single line diagram of a single generator connected through parallel transmission lines to an infinite bus with a TCSC is shown in Fig. 1. The Phillips-Heffron linear model of a SMIB system with PSS, which is shown in Fig. 2, is derived from the following non-linear differential equations (Song and Johns, 1999):

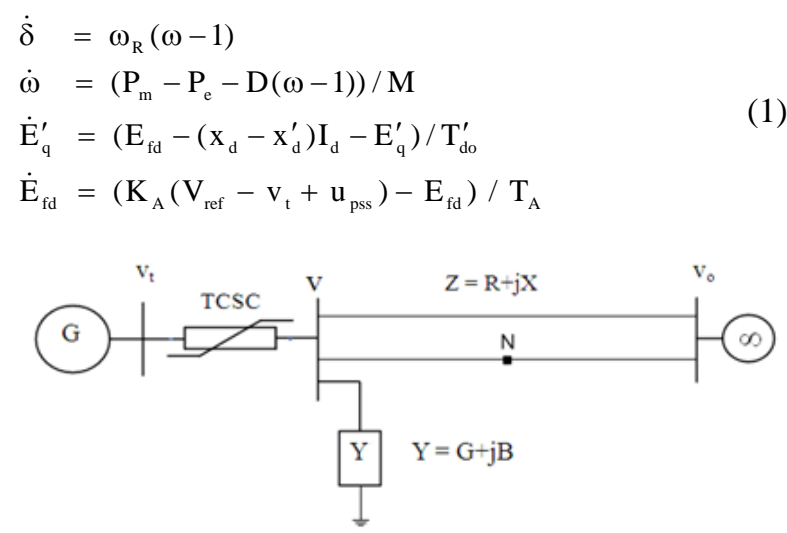

Fig. 1: SMIB power system with a TCSC

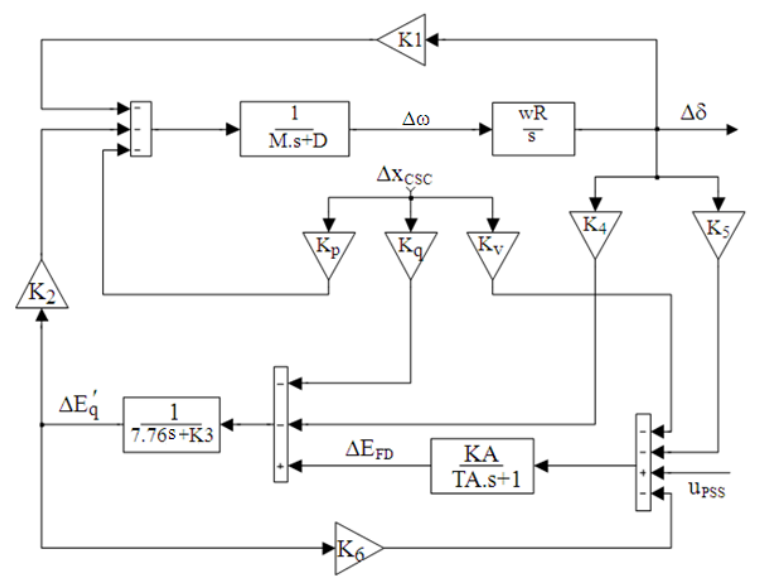

Fig. 2: The Philips-Heffron model of a SMIB power system installed with a TCSC (Song and Johns, 1999) 
Am. J. Applied Sci., 7 (1): 145-152, 2010

Where:

$\omega, \omega_{\mathrm{R}}$ and $\delta=$ The speed, the synchronous speed and rotor angle respectively

$\mathrm{P}_{\mathrm{m}}$ and $\mathrm{P}_{\mathrm{e}}=$ The mechanical and electrical power of the system respectively

$\mathrm{E}_{\mathrm{fd}}$ and $\mathrm{E}_{\mathrm{q}}^{\prime}=$ The field voltage and the internal voltage respectively

$\mathrm{T}_{\mathrm{do}}^{\prime} \quad=$ Open circuit field time constant

$\mathrm{x}_{\mathrm{d}}$ and $\mathrm{x}_{\mathrm{d}}^{\prime}=\mathrm{d}$ axis reactance and transient reactance of the generator, respectively

$\mathrm{I}_{\mathrm{d}} \quad=\mathrm{d}$ axis component of the armature current

$\mathrm{v}_{\mathrm{t}} \quad=$ The generator terminal voltage

$\mathrm{K}_{\mathrm{A}}$ and $\mathrm{T}_{\mathrm{A}}=$ The gain and time constant of the excitation system, respectively

$\mathrm{u}_{\mathrm{pss}} \quad=$ The output signal of the PSS stabilizer

For calculation the constants of Fig. 2, the armature current component $i_{d}$ and $i_{q}$ must be known.

Let $\quad \overrightarrow{\mathrm{i}}=\mathrm{i}_{\mathrm{d}}+\mathrm{ji}_{\mathrm{q}}, \quad \overrightarrow{\mathrm{v}}_{\mathrm{t}}=\mathrm{v}_{\mathrm{td}}+\mathrm{jv}_{\mathrm{tq}}$ and $\overrightarrow{\mathrm{v}}_{\mathrm{o}}=\mathrm{v}_{\mathrm{o}}(\sin \delta+\mathrm{j} \cos \delta)$ where $\delta$ is a torque angle between the infinite bus voltage $\overrightarrow{\mathrm{v}}_{\mathrm{o}}$ and $\overrightarrow{\mathrm{E}}_{\mathrm{q}}^{\prime}$.

From Fig. 1:

$\mathrm{Zi}=(1+\mathrm{ZY}) \mathrm{v}-\mathrm{v}_{\mathrm{o}}$

Equation 2 can be written in matrix form after separating real and imaginary parts:

$\left[\begin{array}{cc}\mathrm{R} & -\mathrm{X} \\ \mathrm{X} & \mathrm{R}\end{array}\right]=\left[\begin{array}{cc}\mathrm{C}_{1} & -\mathrm{C}_{2} \\ \mathrm{C}_{2} & \mathrm{C}_{1}\end{array}\right]\left[\begin{array}{c}\mathrm{v}_{\mathrm{d}} \\ \mathrm{v}_{\mathrm{q}}\end{array}\right]-\mathrm{v}_{\mathrm{o}}\left[\begin{array}{c}\sin \delta \\ \cos \delta\end{array}\right]$

Where:

$$
\begin{aligned}
& \mathrm{C}_{1}=1+\mathrm{RG}-\mathrm{XB} \\
& \mathrm{C}_{2}=\mathrm{XG}+\mathrm{RB}
\end{aligned}
$$

Also from Fig. $1 \vec{v}=\vec{v}_{t}-j X_{C S C} \vec{i}$ the magnitudes of $\mathrm{d}$ and q components of $\overrightarrow{\mathrm{v}}$ can be written in matrix form as:

$$
\left[\begin{array}{l}
\mathrm{v}_{\mathrm{d}} \\
\mathrm{v}_{\mathrm{q}}
\end{array}\right]=\left[\begin{array}{l}
0 \\
1
\end{array}\right] \mathrm{E}_{\mathrm{q}}^{\prime}-\left[\begin{array}{cc}
0 & -\mathrm{x}_{\mathrm{q}} \\
\mathrm{x}_{\mathrm{d}}^{\prime} & 0
\end{array}\right]\left[\begin{array}{l}
\mathrm{i}_{\mathrm{d}} \\
\mathrm{i}_{\mathrm{q}}
\end{array}\right]
$$

Substituting (4) into (3) and solving for $\mathrm{i}_{d}$ and $\mathrm{i}_{\mathrm{q}}$ gives:

$$
\left[\begin{array}{c}
\mathrm{i}_{\mathrm{d}} \\
\mathrm{i}_{\mathrm{q}}
\end{array}\right]=\left[\begin{array}{c}
\mathrm{Y}_{\mathrm{d}} \\
\mathrm{Y}_{\mathrm{q}}
\end{array}\right] \mathrm{E}_{\mathrm{q}}^{\prime}-\frac{\mathrm{v}_{\mathrm{o}}}{\mathrm{Z}_{\mathrm{e}}^{2}}\left[\begin{array}{cc}
\mathrm{R}_{2} & \mathrm{X}_{1} \\
-\mathrm{X}_{2} & \mathrm{R}_{1}
\end{array}\right]\left[\begin{array}{c}
\sin \delta \\
\cos \delta
\end{array}\right]
$$

Where:

$$
\begin{aligned}
& \mathrm{R}_{1}=\mathrm{R}-\mathrm{C}_{2}\left(\mathrm{x}_{\mathrm{d}}{ }_{\mathrm{d}}+\mathrm{X}_{\mathrm{CSC}}\right) \\
& \mathrm{X}_{1}=\mathrm{X}+\mathrm{C}_{1}\left(\mathrm{x}_{\mathrm{q}}+\mathrm{X}_{\mathrm{CSC}}\right) \\
& \mathrm{R}_{2}=\mathrm{R}-\mathrm{C}_{2}\left(\mathrm{x}_{\mathrm{q}}+\mathrm{X}_{\mathrm{CSC}}\right), \\
& \mathrm{X}_{2}=\mathrm{X}+\mathrm{C}_{1}\left(\mathrm{x}_{\mathrm{d}}+\mathrm{X}_{\mathrm{CSC}}\right) \\
& \mathrm{Z}^{2}=\mathrm{R}_{1} \mathrm{R}_{2}+\mathrm{X}_{1} \mathrm{X}_{2} \\
& \mathrm{Y}_{\mathrm{d}}=\left(\mathrm{C}_{1} \mathrm{X}_{1}-\mathrm{C}_{2} \mathrm{R}_{2}\right) / \mathrm{Z}^{2}{ }_{\mathrm{e}} \\
& \mathrm{Y}_{\mathrm{q}}=\left(\mathrm{C}_{1} \mathrm{R}_{1}+\mathrm{C}_{2} \mathrm{X}_{2}\right) / \mathrm{Z}_{\mathrm{e}}{ }_{\mathrm{e}}
\end{aligned}
$$

Linerarizing last equation yields:

$$
\left[\begin{array}{c}
\Delta \mathrm{i}_{\mathrm{d}} \\
\Delta \mathrm{i}_{\mathrm{q}}
\end{array}\right]=\left[\begin{array}{c}
\mathrm{Y}_{\mathrm{d}} \\
\mathrm{Y}_{\mathrm{q}}
\end{array}\right] \Delta \mathrm{E}_{\mathrm{q}}^{\prime}+\left[\begin{array}{l}
\mathrm{F}_{\mathrm{d}} \\
\mathrm{F}_{\mathrm{q}}
\end{array}\right] \Delta \delta+\left[\begin{array}{l}
\mathrm{H}_{\mathrm{d}} \\
\mathrm{H}_{\mathrm{q}}
\end{array}\right] \Delta \mathrm{X}_{\mathrm{CSC}}
$$

Where:

$$
\left[\begin{array}{c}
\mathrm{F}_{\mathrm{d}} \\
\mathrm{F}_{\mathrm{q}}
\end{array}\right]=\frac{\mathrm{v}_{\mathrm{o}}}{\mathrm{Z}_{\mathrm{e}}^{2}}\left[\begin{array}{cc}
-\mathrm{R}_{2} & \mathrm{X}_{1} \\
\mathrm{X}_{2} & \mathrm{R}_{1}
\end{array}\right]\left[\begin{array}{c}
\cos \delta_{\mathrm{o}} \\
\sin \delta_{\mathrm{o}}
\end{array}\right]
$$

and

$$
\left[\begin{array}{l}
\mathrm{H}_{\mathrm{d}} \\
\mathrm{H}_{\mathrm{q}}
\end{array}\right]=\left[\begin{array}{l}
\partial \mathrm{i}_{\mathrm{d}} / \partial \mathrm{x}_{\mathrm{csc}} \\
\partial \mathrm{i}_{\mathrm{q}} / \partial \mathrm{x}_{\mathrm{csc}}
\end{array}\right]
$$

$\mathrm{P}_{\mathrm{m}}$ in Eq. 1 assumed to be constant and $\mathrm{P}_{\mathrm{e}}$ can be represented by two axis as:

$$
\mathrm{P}_{\mathrm{e}}=\mathrm{v}_{\mathrm{tq}} \mathrm{i}_{\mathrm{q}}+\mathrm{v}_{\mathrm{td}} \mathrm{i}_{\mathrm{d}}
$$

Where:

$$
\begin{aligned}
\mathrm{v}_{\mathrm{td}} & =\mathrm{x}_{\mathrm{q}} \mathrm{I}_{\mathrm{q}} \\
\mathrm{v}_{\mathrm{tq}} & =\mathrm{E}_{\mathrm{q}}^{\prime}-\mathrm{x}_{\mathrm{d}}^{\prime} \mathrm{I}_{\mathrm{d}} \\
\mathrm{v}_{\mathrm{t}}{ }^{2} & =\mathrm{v}_{\mathrm{td}}{ }^{2}+\mathrm{v}_{\mathrm{tq}}{ }^{2}
\end{aligned}
$$

So:

$\mathrm{P}_{\mathrm{e}}=\mathrm{i}_{\mathrm{q}} \mathrm{E}_{\mathrm{q}}^{\prime}+\left(\mathrm{x}_{\mathrm{q}}-\mathrm{x}_{\mathrm{d}}^{\prime}\right) \mathrm{i}_{\mathrm{d}} \mathrm{i}_{\mathrm{q}}$

Substituting (6) into the linearized results of (10) gives:

$\Delta \mathrm{P}_{\mathrm{e}}=\mathrm{K}_{1} \Delta \delta+\mathrm{K}_{2} \Delta \mathrm{E}_{\mathrm{q}}^{\prime}+\mathrm{K}_{\mathrm{p}} \Delta \mathrm{x}_{\mathrm{csc}}$

Where:

$$
\left[\begin{array}{c}
\mathrm{K}_{1} \\
\mathrm{~K}_{2} \\
\mathrm{~K}_{\mathrm{p}}
\end{array}\right]=\left[\begin{array}{c}
\partial \mathrm{P}_{\mathrm{e}} / \partial \delta \\
\partial \mathrm{P}_{\mathrm{e}} / \partial \mathrm{E}_{\mathrm{q}}^{\prime} \\
\partial \mathrm{P}_{\mathrm{e}} / \partial \mathrm{x}_{\mathrm{csc}}
\end{array}\right]
$$


From Eq. 1, the following linearized equation can be written:

$\Delta \mathrm{E}_{\mathrm{q}}=\Delta \mathrm{E}_{\mathrm{q}}^{\prime}+\left(\mathrm{x}_{\mathrm{d}}-\mathrm{x}_{\mathrm{d}}^{\prime}\right) \Delta \mathrm{i}_{\mathrm{d}}$

Substitute $\Delta \mathrm{i}_{\mathrm{d}}$ from (6) into (13) yields

$\Delta \mathrm{E}_{\mathrm{q}}=\mathrm{K}_{3} \Delta \mathrm{E}_{\mathrm{q}}^{\prime}+\mathrm{K}_{4} \Delta \delta+\mathrm{K}_{\mathrm{q}} \Delta \mathrm{x}_{\mathrm{csc}}$

Where:

$\mathrm{K}_{3}=1+\left(\mathrm{x}_{\mathrm{d}}-\mathrm{x}_{\mathrm{d}}^{\prime}\right) \mathrm{Y}_{\mathrm{d}}$

$\mathrm{K}_{4}=\left(\mathrm{x}_{\mathrm{d}}-\mathrm{x}_{\mathrm{d}}^{\prime}\right) \mathrm{F}_{\mathrm{d}}$

$\mathrm{K}_{\mathrm{q}}=\left(\mathrm{x}_{\mathrm{d}}-\mathrm{x}_{\mathrm{d}}^{\prime}\right) \mathrm{H}_{\mathrm{d}}$

Deviation of terminal voltage magnitude $\mathrm{v}_{\mathrm{t}}$ can be expressed in terms of $\mathrm{d}$ and $\mathrm{q}$ components as:

$\Delta \mathrm{v}_{\mathrm{t}}=\left(\mathrm{v}_{\mathrm{tdo}} / \mathrm{v}_{\mathrm{to}}\right) \Delta \mathrm{v}_{\mathrm{td}}+\left(\mathrm{v}_{\mathrm{tqo}} / \mathrm{v}_{\mathrm{t} 0}\right) \Delta \mathrm{v}_{\mathrm{tq}}$

Substituting (6) into the linearized results of (4) and then the results substitute in (15) gives:

$\Delta \mathrm{v}_{\mathrm{t}}=\mathrm{K}_{5} \Delta \delta+\mathrm{K}_{6} \Delta \mathrm{E}_{\mathrm{q}}^{\prime}+\mathrm{K}_{\mathrm{v}} \Delta \mathrm{x}_{\mathrm{csc}}$

Where:

$$
\left[\begin{array}{c}
\mathrm{K}_{5} \\
\mathrm{~K}_{6} \\
\mathrm{~K}_{\mathrm{v}}
\end{array}\right]=\left[\begin{array}{c}
\partial \mathrm{v}_{\mathrm{t}} / \partial \delta \\
\partial \mathrm{v}_{\mathrm{t}} / \partial \mathrm{E}_{\mathrm{q}}^{\prime} \\
\partial \mathrm{v}_{\mathrm{t}} / \partial \mathrm{x}_{\mathrm{csc}}
\end{array}\right]
$$

Here, the transfer function of AVR is assumed to be of the simplest form $\frac{K_{A}}{1+s T_{A}}$.

The transfer function of the TCSC can be represented as:

$\dot{\mathrm{x}} \csc =\frac{\mathrm{Kc}\left(\mathrm{x}_{\mathrm{csc}(\mathrm{ref})}+\mathrm{u}_{\mathrm{csc}}\right)-\mathrm{x} \csc }{\mathrm{Tc}}$

where, $x_{c s c(r e f)} K_{c}$ and $T_{c}$ are the reference reactance the gain and time constant of the TCSC respectively.

By linearizing Eq. 1 at an operating condition, the model of the power system with TCSC can be obtained as follows:

$$
\begin{aligned}
\Delta \dot{\mathrm{s}} & =\omega_{\mathrm{R}} \Delta \omega \\
\Delta \dot{\omega} & =\left(-\mathrm{K}_{1} \Delta \mathrm{s}-\mathrm{D} \Delta \omega-\mathrm{K}_{2} \Delta \mathrm{E}_{\mathrm{q}}^{\prime}-\mathrm{K}_{\mathrm{p}} \Delta \mathrm{x}_{\mathrm{csc}}\right) / \mathrm{M} \\
\Delta \dot{\mathrm{E}}_{\mathrm{q}}^{\prime} & =\left(-\mathrm{K}_{4} \Delta \mathrm{s}-\mathrm{K}_{3} \Delta \mathrm{E}_{\mathrm{q}}^{\prime}+\Delta \mathrm{E}_{\mathrm{fd}}-\mathrm{K}_{\mathrm{q}} \Delta \mathrm{x}_{\mathrm{csc}}\right) / \mathrm{T}_{\mathrm{do}}^{\prime} \\
\Delta \dot{\mathrm{E}}_{\mathrm{fd}} & =\frac{-\mathrm{K}_{\mathrm{A}}\left(\mathrm{K}_{5} \Delta \mathrm{s}-\mathrm{K} 6 \Delta \mathrm{E}_{\mathrm{q}}^{\prime}-\mathrm{K}_{\mathrm{v}} \Delta \mathrm{x}_{\mathrm{csc}}+\mathrm{u}_{\mathrm{pss}}\right)-\Delta \mathrm{E}_{\mathrm{fd}}}{\mathrm{T}_{\mathrm{A}}}
\end{aligned}
$$
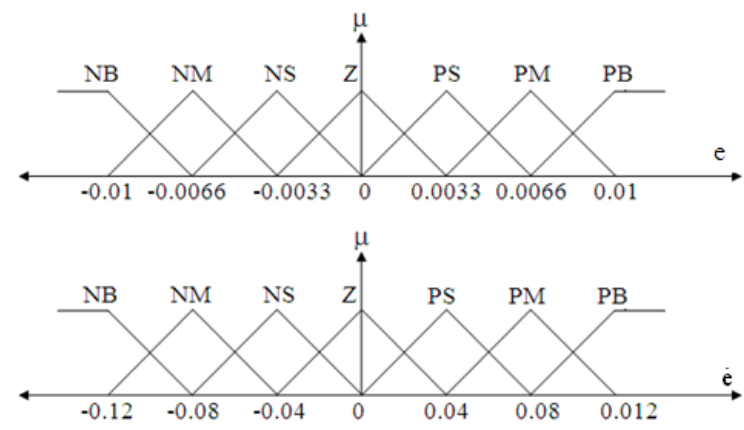

Fig. 3: Membership functions for the proposed controller of error, errors time derivative

The linearized model can be represented in the state-space form:

$\dot{\mathrm{x}}=\mathrm{Ax}+\mathrm{Bu}$

Where:

$\mathrm{A}=$ The state matrix

$\mathrm{B}=$ Input matrix

$\mathrm{u}=$ Input vectors

$\mathrm{x}=$ The state vector

Proposed controller: As mentioned earlier, Takagi-Sugeno fuzzy models are well appropriate for modeling nonlinear systems by interpolating multiple linear models, are also suitable for mathematical analysis and lend themselves to adaptive techniques (Tsoukalas and Uhric, 1997). The output variable in Takagi-Sugeno fuzzy rules is given in terms of a functional relation of the inputs. These rules can be written typically as:

If $\mathrm{x}_{1}$ is $\mathrm{D}_{1}$ and $\mathrm{x}_{2}$ is $\mathrm{D}_{2}$ Then output $=\mathrm{f}\left(\mathrm{x}_{1}, \mathrm{x}_{2}\right)$

where, $\mathrm{f}$ is a function of the inputs $\mathrm{x}_{1}$ and $\mathrm{x}_{2}$.

When applying Sugeno rules to the parameters of a PI controller, the result will be a fuzzy "supervisor" changing the parameters of the controller (Tsoukalas and Uhric, 1997).

The control structure of the TCSC can be written as:

$\mathrm{u}(\mathrm{t})=\mathrm{K}_{\mathrm{P}} \mathrm{e}+\mathrm{K}_{\mathrm{I}} \int \mathrm{edt}$

Where:

e $\quad=\Delta \omega$

$\mathrm{K}_{\mathrm{P}}$ and $\mathrm{K}_{\mathrm{I}}=$ The proportional and integral controller gains respectively 
Here, the gains of the PI controller are modified according to the disturbances of the system. The Takagi-Sugeno fuzzy inference engine was chosen and the range of the controller is selected suitably to enhance the output performance of the system. The first step in designing the fuzzy logic controller is choosing the controller variables (controller inputs and outputs). In this study, they are the error and its time derivative. Seven triangle membership functions are employed for the inference mechanisms i.e., Negative Big (NB), Negative Medium (NM), Negative Small (NS), Zero (Z), Positive Small (PZ), Positive Medium (PM) and Positive Big (PB). The membership functions of e, è for the proposed controller are shown in Fig. 3.

In this study, zero order Sugeno controller is used. Hence (21) can be written as:

If eis $L_{k}$ and eis $M_{k}$ Then Gain is $Z_{k}$

Where:

$\mathrm{L}_{\mathrm{k}}, \mathrm{M}_{\mathrm{k}}=$ Fuzzy sets

$\mathrm{Z}_{\mathrm{k}} \quad=$ A constant

The fuzzy set rules are given in Table 1. Centroid method is used in deffuzzification process which converts linguistic variables to crisp values using normalized membership functions and output gains. The process depends on the output fuzzy set. The proposed FGPI controller is presented in Fig. 4.

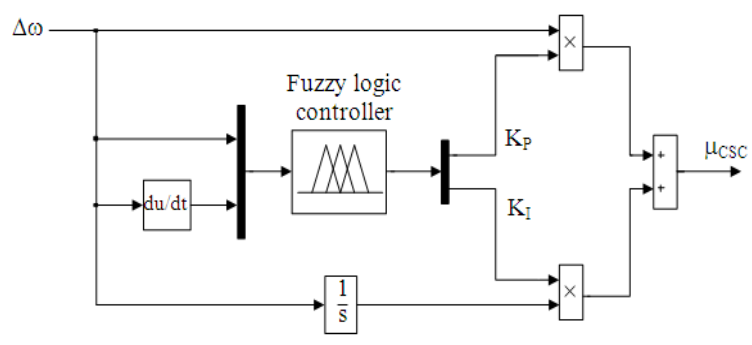

Fig. 4: The proposed FGPI controller

Table 1: Fuzzy logic rules for the proposed controller.

\begin{tabular}{|c|c|c|c|c|c|c|c|}
\hline \multirow[b]{2}{*}{$\dot{\mathrm{e}}$} & \multicolumn{7}{|l|}{ e } \\
\hline & NB & NM & NS & Z & PS & PM & PB \\
\hline NB & PB & PB & PB & PM & PM & PS & $\mathrm{Z}$ \\
\hline NM & PB & $\mathrm{PM}$ & PM & PM & PS & $\mathrm{Z}$ & NS \\
\hline NS & PB & $\mathrm{PM}$ & PS & PS & Z & NS & NM \\
\hline Z & PM & $\mathrm{PM}$ & PS & Z & NS & NM & NM \\
\hline PS & PM & PS & Z & NS & NS & NM & NB \\
\hline PM & PS & Z & NS & NM & NM & NM & NB \\
\hline PB & Z & NS & NM & NM & NB & NB & NB \\
\hline
\end{tabular}

\section{RESULTS}

The system eigenvalues without controller are $0.3 \pm 4.96$ and $-10.39 \pm 3.28 \mathrm{j}$. Hence the unstable system due to the negative damping of electromechanical mode needs to be stabilized by the supplementary TCSC control. The proposed FGPI is designed for TCSC of the SMIB system. The system is subjected to different disturbances and under different loading conditions. The response of the system to different disturbances is presented to prove the superiority of the proposed controller over simulated annealing-based TCSC stabilizer (SACSC) and Simulated Annealing-Based Power System Stabilizer (SAPSS) (Abido, 2000). The data of the SACSC and SAPSS are given by (Abido, 2000). The data of the system are:

$\mathrm{M}=9.26, \quad \mathrm{~T}_{\mathrm{do}}^{\prime}=7.76, \mathrm{D}=0.0, \mathrm{x}_{\mathrm{d}}=0.973, \mathrm{x}_{\mathrm{d}}^{\prime}=0.19$, $\mathrm{x}_{\mathrm{q}}=0.55, \mathrm{R}=-0.034, \mathrm{X}=0.997, \mathrm{~g}=0.249, \mathrm{~b}=0.262$, $\mathrm{K}_{\mathrm{A}}=50, \mathrm{~T}_{\mathrm{A}}=0.05, \mathrm{~K}_{\mathrm{C}}=1.0, \mathrm{~T}_{\mathrm{C}}=0.05, \mathrm{v}_{\mathrm{t}}=1.05, \mathrm{~T}_{\mathrm{w}}=5$

In this study, the simulation is implemented by using MATLAB Simulink program and MATLAB Fuzzy Logic toolbox.

Case 1: In this case the proposed stabilizer was tested at nominal load condition i.e., $\mathrm{P}=1.0$ and $\mathrm{Q}=0.015$ $\mathrm{pu}$, with a 6-cylce three phase fault at mid point $(\mathrm{N})$ of second transmission line as shown in Fig. 1. The system time domain responses under different controllers are shown in Fig. 5 and 6. The results show the frequency deviations and the torque angle deviation of the system with different controllers. The initial torque angle is 0.1 .

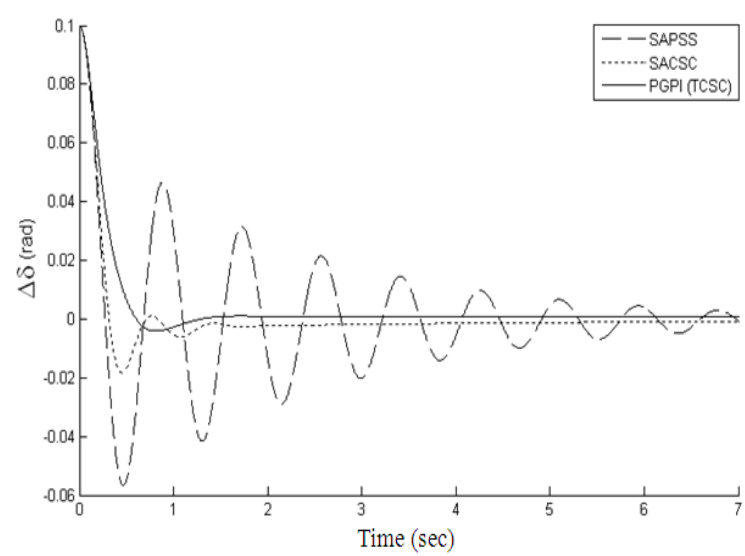

Fig. 5: Torque angle response for case 1 
Case 2: Here, the uncertainty of the synchronous generator parameter variation is considered. Inertia constant varied for $\pm 30 \%$. The initial torque angle is 0.1 . The system response with upper and lower bound inertia constant variation under proposed controller is shown in Fig. 7 and 8. In order to compare the proposed controller with other schemes the performance robustness of the three schemes are computed by using second norm (Norm) as:

$$
\begin{aligned}
& \operatorname{Norm}_{U B P}=\left\{\sum_{i=0}^{k}\left[x_{N P}(i T)-x_{U B P}(i T)\right]^{2}\right\}^{\frac{1}{2}} \\
& \operatorname{Norm}_{L B P}=\left\{\sum_{i=0}^{k}\left[x_{N P}(i T)-x_{L B P}(i T)\right]^{2}\right\}^{\frac{1}{2}}
\end{aligned}
$$

where, $\mathrm{x}_{\mathrm{NP}}(\mathrm{iT}), \mathrm{x}_{\mathrm{UBP}}(\mathrm{iT})$ and $\mathrm{X}_{\mathrm{LBP}}(\mathrm{iT})$ represent the value of any state $x$ at $i$-th instant of time, when the system parameters are at the nominal values, upper and lower bounds respectively.

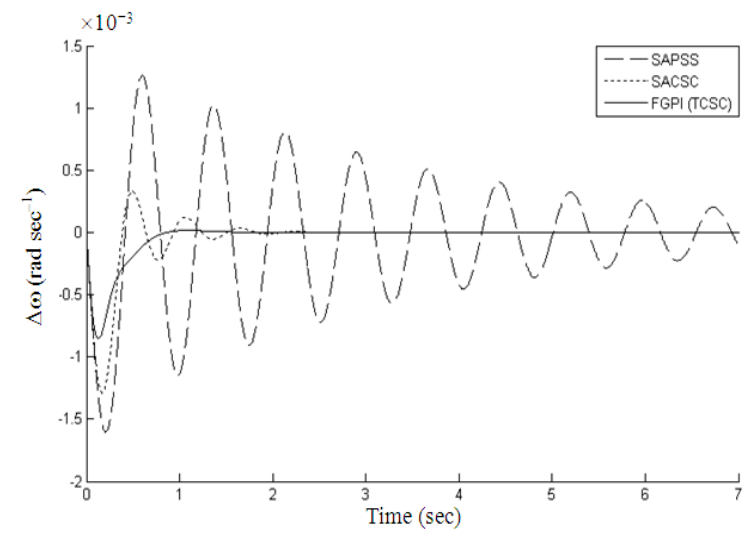

Fig. 6: Frequency response for case 1

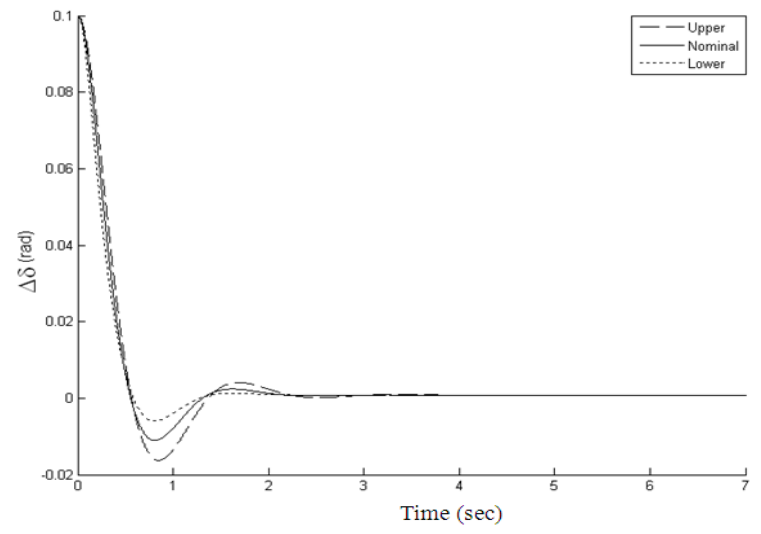

Fig. 7: Torque angle response for case 2
The numerical results of the performance robustness are presented in Table 2

Case 3: In this case a different operating condition is considered. The system subjected to a 6 cycle three phase fault disturbance when the operating condition is $\mathrm{P}=1.1$ and $\mathrm{Q}=0.1 \mathrm{pu}$ and field time constant $\left(\mathrm{T}_{\mathrm{do}}^{\prime}\right)$ decreases by $30 \%$. Time domain response of the system with the three controllers is shown in Fig. 9 and 10. The voltage profile with the proposed controller is shown in Fig. 11. The control input signal as an important factor for practical implementation is depicted in Fig. 12 applying the three schemes.

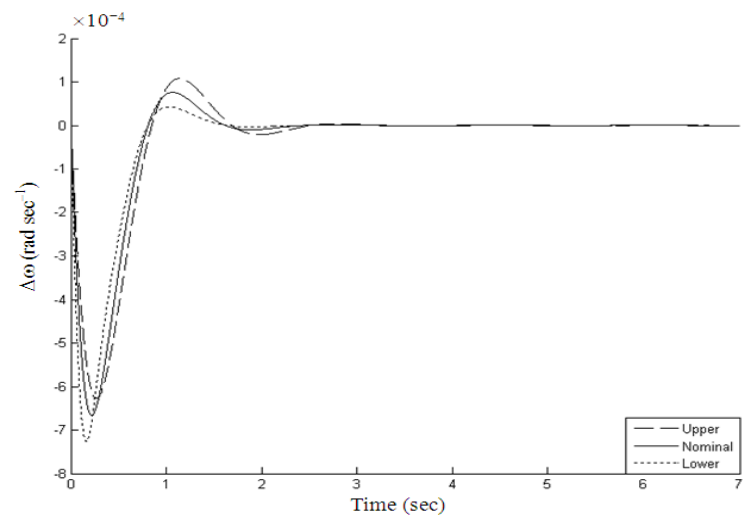

Fig. 8: Frequency response for case 2

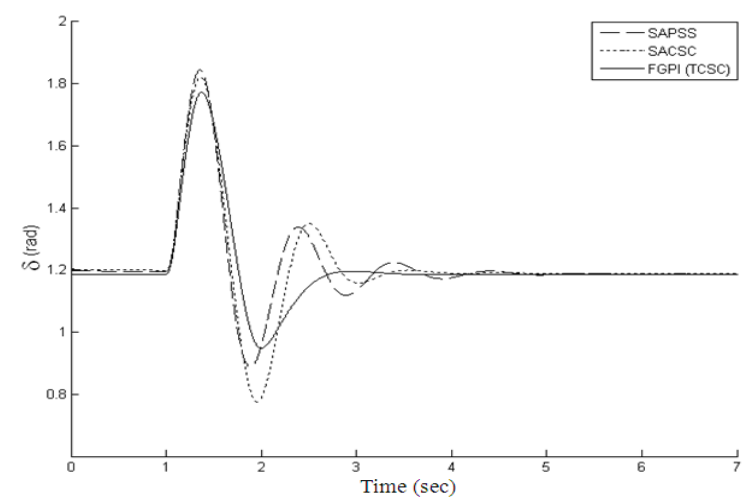

Fig. 9: Torque angle deviation for case 3

Table 2: Performance robustness with different controllers

\begin{tabular}{lllllll}
\hline & ASPSS & & ASCSC & & \multicolumn{2}{l}{ FGPI (TCSC) } \\
& ------------ & -------- \\
& Norm $_{\text {UBP }}$ & Norm $_{\text {LBP }}$ & Norm $_{\text {UBP }}$ & Norm $_{\text {LBP }}$ & Norm $_{\text {UBP }}$ & Norm $_{\text {LBP }}$ \\
\hline$\Delta \omega$ & 0.0192 & 0.0290 & 0.0054 & 0.0073 & 0.0020 & 0.0023 \\
$\Delta \delta$ & 1.1989 & 1.5603 & 0.3778 & 0.3994 & 0.1619 & 0.1520 \\
\hline
\end{tabular}




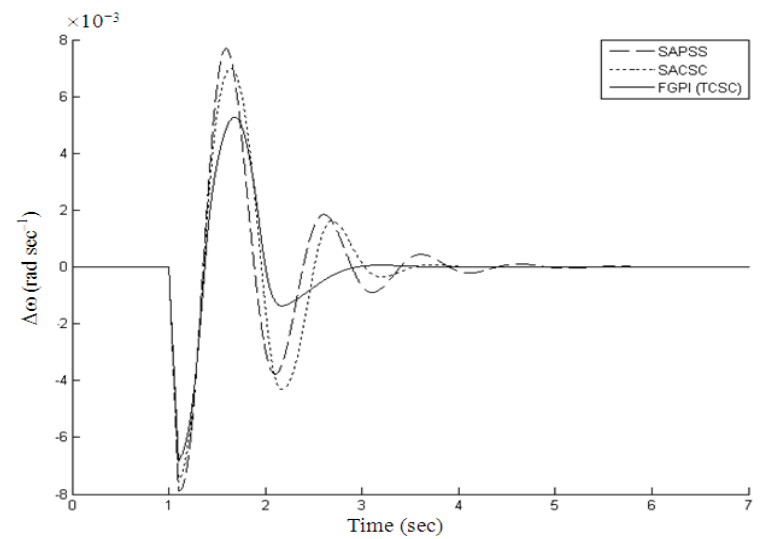

Fig. 10: Frequency response for case 3

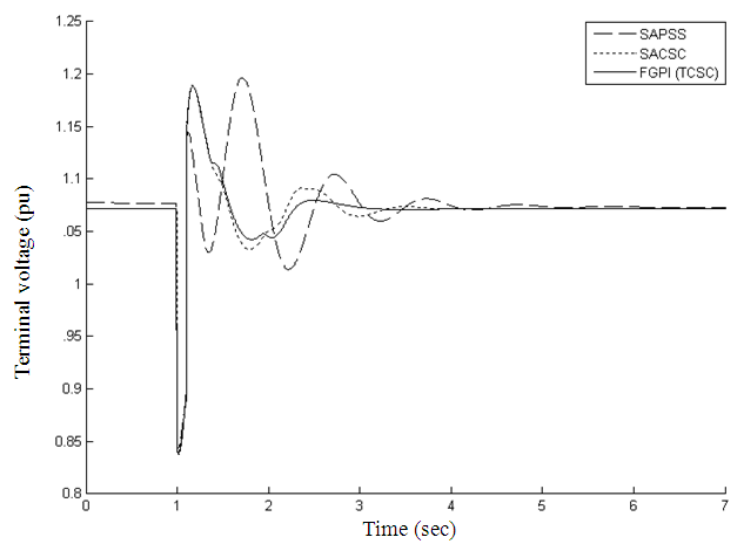

Fig. 11: Terminal voltage response for case 3

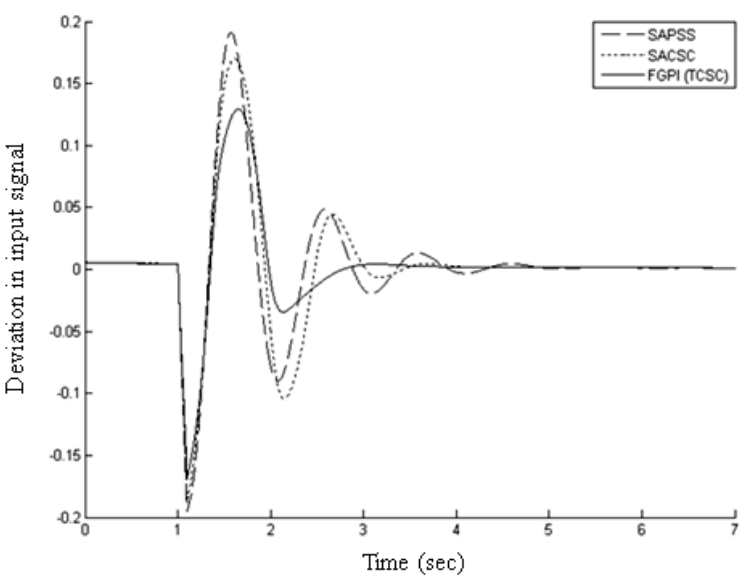

Fig. 12: Input signal response for case 3

\section{DISCUSSION}

It is clear from the Case 1 that settling time of the proposed controller is much faster and has smaller overshoots in comparison to the other approaches as demonstrated in Fig. 5 and 6. In addition no undershoots appear with the proposed controller. In Case 2, Fig. 7 and 8 show that the proposed controller is capable of maintaining stability with the synchronous generator parameter variations. Table 2 demonstrates that the Norms of the deviation for both state variables with proposed controller are less than other schemes. Case 3 results show that the proposed stabilizer provides the best damping characteristics and enhance greatly the first swing stability as shown in Fig. 9 and 10. Furthermore the voltage profile improved with the proposed controller as shown in Fig. 11. Figure 12 shows that the control input signal of the proposed controller is smoother and less oscillatory.

\section{CONCLUSION}

In this study, a new Takagi-Sugeno fuzzy gains scheduled proportional and integral controller was proposed for the Thyristor-Controlled Series Capacitor (TCSC) to improve the performance of the power system.

The simulations of the proposed controller on the Single Machine Infinite Bus (SMIB) power system indicate robust performance with load changes and disturbances. In addition, this controller is simple in implementation and robust against parameter uncertainties.

The results of the proposed controller were compared with SAPSS and SACSC which are also simulated in this study. The comparison revealed that the proposed FGPI for TCSC based stabilizer has shorter settling time, smaller overshoots and no undershoots in comparison to the other approaches. Moreover, numerical results of performance robustness demonstrate that the proposed controller is more robust against parameter variations than the other approaches.

Therefore, it can be concluded that the proposed controller is robust and more effective in damping of low frequency oscillation and improving power system stability resulting in better system stability.

\section{REFERENCES}

Abdel-Magid, Y.L. and M.A. Abido, 2004. Robust coordinated design of excitation and TCSC-based stabilizers using genetic algorithms. Int. J. Elect. Power Syst. Res., 69: 129-141. DOI: 10.1016/j.epsr.2003.06.009

Abido, M.A., 2000. Pole placement technique for PSS and TCSC-based stabilizer design using simulated annealing. Elect. Power Energy Syst., 22: 543-554. DOI: 10.1016/S0142-0615(00)00027-2 
Al-Awami, A.T., Y.L. Abdel-Magid and M.A. Abido, 2007. A particle-swarm-based approach of power system stability enhancement with unified power flow controller. Elect. Power Energy Syst., 29: 251-259. DOI: 10.1016/j.ijepes.2006.07.006

Barreiros, J.A.L., A.M.D. Ferreira, T. Tavares-da-Costa Jr., W. Barra Jr. and J.A.P. Lopes, 2005. A neural power system stabilizer trained using local linear controllers in a gain-scheduling scheme. Int. J. Elect. Power Energy Syst., 27: 473-479. DOI: 10.1016/j.ijepes.2005.02.006

Dash, P.K. and S. Mishra, 2003. Damping of multimodal power system oscillations by FACTS devices using non-linear Takagi-Sugeno fuzzy controller. Int. J. Elect. Power Energy Syst., 25: 481-490. DOI: 10.1016/S0142-0615(02)00084-4

Gerbex, S., R. Cherkaoui and A.J. Germond, 2001. Optimal location of multi-type facts devices in a power system by means of genetic algorithms. IEEE Trans. Power Syst., 16: 537-544. DOI: 10.1109/59.932292

Gouveia, E.M. and M.A. Matos, 2009. Symmetric AC fuzzy power flow model. Eur. J. Operat. Res., 197: 1012-1018. DOI: 10.1016/j.ejor.2007.12.044

Hang, C.C., T.H. Lee and W.K. Ho, 1993. Adaptive Control. 1st Edn., International Society of America. Instrument Society of America, ISBN: 1556174772, pp: 261.

Khan, L., G.J. Rogers and C.A. Lozano, 2004. Intelligent control of FACTS for damping power system low frequency oscillations. Proceedings of INMIC 8th International Multitopic Conference, Dec. 24-26, IEEE Xplore Press, USA., pp: 731-736. DOI: 10.1109/INMIC.2004.1492986

Lu, Q., W. Wang, C. Shen, S. Mei, M. Goto and A. Yokoyama, 2002. Intelligent optimal sieving method for FACTS device control in multi-machine systems. Int. J. Elect. Power Syst. Res., $\quad$ 62: 209-214. DOI: 10.1109/WCICA.2000.859912

Machowiski, J., J.W. Bialek and J. Bumby, 1998. Power Systems Dynamics and Stability. 1st Edn., Wiley, England. ISBN: 10: 0471956430, pp: 484.
He, N., R. Liu and D. Xu, 2005. The study of UPFC fuzzy control with self-adjustable factor. Proceedings of the IEEE/PES Transmission and Distribution Conference and Exhibition, Aug. 18-18, IEEE Xplore Press, USA., pp: 1-5. DOI: 10.1109/TDC.2005.1546745

Paserba, J.J., 2004. How FACTS controllers benefit AC transmission systems. Proceeding of the Power Engineering Society General Meeting, June 10-10, IEEE Xplore Press, USA., pp: 1257-1262. DOI: 10.1109/PES.2004.1373058

Qureshi, M.F., J.K. Gabel, C.S. Khande and I.C. Bharti, 2007. Application of hybrid system control method for real-time power System stabilization. Fuzzy Sets Syst., 158: 2687-2705. DOI: 10.1016/j.fss.2007.06.007

Song, Y.H. and A.T. Johns, 1999. Flexible AC Transmission Systems (FACTS). 1st Edn., Institution of Engineering and Technology, Hong kong, pp: 596.

Tan, X., L. Tong, N. Zhang, Z. Yin, D. Zhang and Z. Wang, 1998. A fuzzy control scheme for thyristor-controlled series compensation in transients of power systems. Proceedings of the International Conference on Power System Technology, Aug. 18-21, IEEE Xplore Press, Beijing, pp: 441-445. DOI: 10.1109/ICPST.1998.729002

Tan, X., N. Zhang, L. Tong and Z. Wang, 2000. Fuzzy control of thyristor-controlled series compensator in power system transients. Fuzzy Sets Syst., 110: $429-436 . \quad$ DOI: 10.1016/S0165-0114(98)00103-1

Tsoukalas, L.H. and R.E. Uhric, 1997. Fuzzy and Neural Approaches in Engineering. 1st Edn., John Wiley and Sons, USA., ISBN: 0-471-16003-2.

Venayagamoorthy, G.K., 2005. Optimal control parameters for a UPFC in a multimachine using PSO. Proceedings of the 13th International Conference on Intelligent Systems Application to Power Systems, Nov. 6-10, IEEE Xplore Press, Arlington, VA., pp: 1-6. DOI: 10.1109/ISAP.2005.1599312 